\title{
"Cultural Astronomy Beyond Paradigms". The 27th Annual Conference of the European Society of Astronomy in Culture, Bern, Switzerland, 5th-7th September 2019
}

\section{Emilia Pásztor \\ Türr István Museum, Hungary \\ pasztoremilia@tolna.net}

The 25th conference of the European Association of Archaeologists (EAA), entitled "Beyond Paradigms", was held in Bern from 4th to 7th September, 2019. When Felipe Criado-Boado, the EAA's president, made an official proposal for a joint meeting for EAA and the European Society of Astronomy in Culture (SEAC) last year, the SEAC executive committee considered it an exceptional occasion that the society could not miss. SEAC's committee also felt that 2019 was symbolically the right time for a joint EAA and SEAC conference, as it was both the 100th anniversary of the Dyson-Eddington-Davidson experiment that first tested general relativity and the 50th anniversary of the Moon landing. However, this was not the first time that there was a cultural astronomy session at an EAA conference - the first instance was actually in Bournemouth in 1999, where an archaeoastronomy roundtable was organised. There was also a cultural astronomy session at the EAA conference in 2002 in Thessaloniki.

At Bern, three sessions were devoted to cultural astronomy. The first of these was Session 233, organised by Lionel Sims and Roslyn Frank, entitled "Cultural Astronomy and Ontology: How Celestial Objects and Events Have Featured in the Belief Systems and Cosmologies of Different Societies". This session invited scholarly contributions that addressed how celestial objects and events have been integrated into belief systems across the world. Twelve presentations tried to answer questions such as whether ethnographic analogies help to develop methods and theories of cultural astronomy, whether our concepts are sufficiently sensitive to capture and respect the details of a local cosmology or whether there is any connection between the cosmologies of the world. Michael Rappenglück offered a general presentation of archaic cosmology models, highlighting the commonality of these models. Roslyn Frank clearly demonstrated how closely cultural anthropology, ethnohistory and archaeology are related to cultural astronomy 
through celestial projections of bear ceremonialism from the Upper Palaeolithic to the present. Taking an art historical approach Mies Hayden investigated how the concept of the rainbow among the San of southern Africa - indigenous hunter-gatherers also known as the Bushmen - has resonance with to a multi-coloured painted motif at the "rainbow mystery shelter" in the Cederberg municipality of the Western Cape, South Africa.

The orientation of a monument can also be a marker for cosmology. This can be expressed in a simple way, such as seen in an unusual architectural structure located in the Altos de Arica (south-central Andes) (presented by Antonio César González-García, Thibault Saintenoy and Marta Crespo) and in the Maltese "temples" (presented by Tore Lomsdalen), or in a sophisticated way, as in the world-famous Angkor Wat temple built in the early twelfth century (presented by William Romain). However, an ancient structure may have a more complex cosmological "secret". To reveal these requires a combination of landscape archaeology and archaeoastronomy, as Lionel Sims and Frank Prendergast indicated in their respective presentations on the West Kennet palisades at Avebury and on the Neolithic passage tomb tradition in Ireland. Barbara Rappenglück and Emilia Pásztor suggested innovative methods to demonstrate that even the ornamental motifs of vessels can involve cosmic symbolism.

The second session (247) was organised by Michael Rappenglück and Georg Zotti: "Frontiers in Theory, Methodology and Education within Cultural Astronomy". It focused on the theoretical, methodological and educational precepts of cultural astronomy. This endeavour and its results made it one of the most important sessions, since it raised important issues not only for archaeologists but also for SEAC members.

The session began with a critical lecture by myself, in which I raised questions about the orientation of prehistoric structures and their commonly accepted astronomical targets. The most important point to be stressed is that because the orientations of these structures depend on the purposes for which they were used, the first necessity is to clarify the function and role of a particular structure before attempting to interpret the data. Archaeoastronomical publications, for the most part, present an unfinished task, as they merely seek out which celestial body the possible orientation target may be.

Based on his research concentrating on the connections between astronomy and the monumental architecture of the prehistoric Chacoan culture, Andrew Munro presented an excellent and instructive counterexample. He shared his experience of three instances of collaboration between archaeologists and archaeoastronomers, and highlighted a range of both successful and failed joint approaches. He discussed how the definition of research questions, the backgrounds and skills of the researchers and research teams and the collaborative process all had a significant impact on outcomes.

Stanislaw Iwaniszewski, in his presentation, drew attention to how important it is personally to observe the astronomical phenomena at archaeoastronomical sites while participating in a community event. In this experience an observer cannot only perceive nearly the same events as the sky watchers did in the remote past, but also feel similar relationships between the human and natural environment. Michael Rappenglück analysed the theoretical position of archaeoastronomy between science and speculation as applied to Palaeolithic case studies, while through the fine example of the Bronze 
Age / Iron Age Chiemgau meteorite impact Barbara Rappenglück exemplified clearly the difficulties of proving catastrophic paradigms. In an excellent presentation Rita Gautschy re-investigated the usefulness of ancient astronomical observations in ancient Egypt and Mesopotamia for dating purposes, clearly demonstrating the conditions under which the data can be used and what expertise is required.

Computational visualisations are often favoured, as they provide a far greater opportunity to understand the choices of ancient people. Georg Zotti gave an overview of the various aspects in which Stellarium, an open-source desktop planetarium, can help scientists recreate past views of the sky over landscapes and cultures of the past. His most ambitious improvement is the addition of a time-aware 3D rendering module which allows interactive walkthroughs of virtual landscapes, so that georeferenced and timeaware site reconstructions can be combined with the simulated skies of past millennia. Its rendering quality is also sufficient for higher-quality models geared towards public outreach. Zotti also requested that the audience could help to further improve the software with culturally determined features. Gail Higginbottom showed an example based on how Stellarium could provide new data for prehistoric Scotland. These visualisations can support the education of students and the general public with regard to cultural astronomy, and two presentations reported on cultural astronomy in education: Steven Gullberg discussed the importance of looking for the potential use of astronomy in any culture, while Jarita Holbrook described her series of archaeoastronomical courses that divided cultural astronomy content into broad regions such as Africa, North America and the Pacific. Her aim is that the students learn critical thinking, how to formulate and test hypotheses and how to interpret cultural astronomy data.

Session 248, "The Archaeology of Astronomy: Concepts of Space and Time Materialised in Cultures", was organised by Ivan Šprajc and Juan Antonio Belmonte Avilés. This session was intended to illustrate the potential of archaeoastronomy, its relevance to archaeology and the place it deserves within a broader framework of anthropological disciplines.

The majority of the session was devoted to town orientation. For example, Antonio César González-García reviewed the location and urban layout of three important cities in antiquity across three continents, explaining that the sky appeared to have been a determining factor in the location of an urban centre in the Supe Valley (Peru) as well as at Petra (Jordan) and Rome (Italy). As a result of many years of archaeoastronomical research Ivan Šprajc summarised how Mesoamerican architecture and urbanism reflect cosmological concepts. He revealed that the civic and ceremonial buildings were largely oriented on the basis of astronomical and calendrical considerations, and that these criteria, notwithstanding regional and temporal variations in orientation patterns, were fundamentally the same over extensive areas and long periods. Ayse Alpay investigated whether the founders of the city at Kerkenes Dağ, Turkey had deliberately incorporated astronomical knowledge into their city planning, and Marco Garcia-Quintela and his team presented a preliminary report on the study of the orientations of 60 Gallo-Roman towns, focusing on towns founded at the time of Augustus. They discovered that these towns, developed while the conquest of Gaul was still recent, incorporated orientations relating 
to Gallic beliefs. Further, Marina De Franceschini and Giuseppe Veneziano claimed that at Avenches, once the capital of Helvetia, there was a summer solstice alignment.

Nicholas Campion's presentation on "Archaeology and the Materiality of Astrology" addressed the relationship between astrology and architecture through the former's role in the foundation of cities, notably Byzantium, Baghdad and Cairo. His conclusion was remarkable: if astrology, as a form of cultural astronomy, had a role in the creation of notable archaeological sites, then the history of astrology itself as a system of thought which flourished in the classical and medieval worlds can be considered through archaeological examples. Juan Belmonte looked at the role the observation of the sky played in the formation of a complex society, as shown by the development and success of Old Kingdom Egypt, while Eberhard Zangger talked about the astral concern of Bronze Age Anatolia. The world-famous Hittite rock sanctuary of Yazılıkaya, adjacent to Hattuša, contains over 90 rock-cut reliefs of deities, humans, animals and mythical figures dating to the second half of the thirteenth century BCE. He argued that the reliefs in Chamber A at the site are arranged in groups for the purpose of keeping track of lunar months, the days of a lunar month, and years.

There were also presentations that attempted to identify orientation targets. Silvia Motta, Adriano Gaspani and Frédéric Heller used satellite images to measure astronomical orientations of Middle Bronze Age structures and burials at Bonlez, Belgium. Radoslaw Palonka and his team investigated possible markers of winter solstice and other ceremonial events in ancient Pueblo rock art. Garcia-Quintela, David Espinosa-Espinosa and César González-García discussed the problem of the orientations of 79 Gallo-Roman sanctuaries, focusing on deviations from eastern orientations.

Eva Spinazzè studied ten Cistercian complexes situated in northern Italy and Switzerland, using a careful methodology that took account of all available sources. In each case she found a precise alignment - a liaison with the sky - towards the setting or rising Sun on liturgical feast days, mainly toward the two main feasts of Mary: the Annunciation on 25th March and the Assumption on 15th August (according to the Julian calendar). This was the case whether their position was in a flat or mountainous setting. Moreover, these results reinforced her findings for a further 220 sacred buildings.

The Southern Cross as a target or depiction was the focus of several presentations. Maitane Urrutia-Aparicio and Juan Belmonte revisited the phenomenon of the orientation of the Menorca taulas, while Christiaan Sterken argued that the constellation can be found amongst the rock art of Argentina and southern France.

In the same session, Hans Martz de la Vega explored the traces of a possible complex system of belief that may be found in the archaeological zone of Malpasito in Tabasco, Mexico, involving relationships between the mountains, the Sun and concepts of the soul, the human body and personhood.

The most important event was session 338, a roundtable that was intended to bring together archaeologists and archaeoastronomers for a discussion entitled "Archaeology and Cultural Astronomy: Bridging the Gap between Trench and Sky". The presidents of the two societies, César González-García (SEAC) and Felipe Criado-Boado (EAA), were its main organisers. They considered the opportunity to celebrate the 27 th annual meeting 
of SEAC together with the 25th annual meeting of the EAA as a key moment for engaging in a fruitful dialogue between the two disciplines, and to bridge the gap which still exists. Apart from the two presidents, there were short presentations by Sophie Hueglin (vicepresident, EAA), Ivan Šprajc (vice-president, SEAC), Clive Ruggles and Amanda Chadburn on the significance but also the difficulties of cooperation between archaeology and astronomy. At the end of the session they opened the floor for comments and discussion from the general audience. Questions raised included:

- Should the sky be a relevant concept for archaeology?

- Does cultural astronomy provide answers for questions not (yet) posed by archaeology?

- Are we (cultural astronomers and archaeologists) asking the same questions?

Unfortunately, the roundtable did not achieve its original purpose. About 20 participants took part, but these were mainly SEAC members, and therefore the questions and comments reflected only their views. The lack of engagement by archaeologists meant that the joint conference did not achieve its main goal of increasing the professional recognition of cultural astronomy among archaeologists. However, we could listen to carefully prepared presentations and hear about exemplary collaborative projects in Andrew Munro's presentation on the links between astronomy and monumental architecture in prehistoric Chacoan culture, and in Radoslaw Palonka and his team's joint research project undertaken in southwestern Colorado. Also, Clive Ruggles' notable plenary presentation "Challenges for Archaeoastronomy" in particular could have raised interest amongst the archaeologists. He noted with examples how archaeoastronomy provides a set of tools and practices available to archaeologists wishing to investigate tangible links between the material record and observable phenomena in the sky. He confirmed that the term "skyscape archaeology" expresses perfectly that archaeoastronomical studies are better integrated within broader archaeological investigations rather than being regarded as a distinct "interdiscipline".

More generally, despite the high quality of the presentations, the SEAC sessions were not well attended by archaeologists. Generally, 30 to a maximum of 50 people attended the lectures. This number is only slightly higher than the number of SEAC members attending the conference (a number that was significantly smaller than for other conferences, perhaps due to Bern being the fifth-most expensive city in the world). The greatest number of questions relating to archaeology were in Session 248, perhaps because the word "archaeology" was included in the title and so drew attention to itself. Archaeoastronomical posters were merged into the conference posters and were not thematically grouped. Thus, not all poster presentations were found. A strategically wellplanned promotion would have helped for better recognition of SEAC. We have missed the chance.

What final conclusions can we draw from the experience of the joint SEAC-EAA conference? First of all, SEAC should continue to organise its own conferences independently, as astronomy represents the connecting link between the various subfields of 
cultural astronomy. Researchers who attend these events are already involved and they can support and encourage each other with their experiences and results.

Should SEAC participate in another such conference in the future, where cultural astronomy is relevant to the conference theme? If we really want cultural astronomical research to receive recognition in the relevant disciplines, then the answer to this question can only be YES. And we must work for it, because it would accelerate the recognition of cultural astronomy. One way of doing this could be consciously to convey the relevant research results of SEAC members at conferences in other disciplines. For example, those who work on ancient Egyptian issues should offer sessions in Egyptology conferences, since Egyptologists have the expertise to evaluate the results and discuss them at an appropriately professional level. We should never be afraid of negative comments from the archaeological side, if we are convinced about our results. Discussions are what make the scientific world function and develop. The SEAC committee should therefore undertake to encourage the organisation of thematic sections at relevant conferences. Such a strategy would certainly increase the international acceptance of cultural astronomy and also fulfil the objectives that have now been set. 